\title{
AUTOMATIC SHEET-PILING SYSTEM FOR ISOLATION BARRIERS AGAINST TRAFFIC-INDUCED GROUND VIBRATIONS
}

\author{
Jori Montonen ${ }^{1}$, Erno Keskinen ${ }^{1}$, Mehdi Bahrekazemi ${ }^{2}$, Anders Bodare ${ }^{2}$, \\ Robert Hildebrand ${ }^{3}$, Michel Cotsaftis ${ }^{4} \&$ Yrjö Raunisto ${ }^{5}$
}

\author{
${ }^{1}$ Laboratory of Machine Dynamics, Tampere University of Technology \\ P.O.Box 589, FIN-33101 Tampere, Finland \\ Email:jori.montonen@tut.fi \\ ${ }^{2}$ Division of Soil and Rock Mechanics, The Royal Institute of Technology \\ Stockholm, Sweden \\ Email: kazemi@aom.kth.se \\ ${ }^{3}$ The M. W. Laboratory for Sound and Vibration Research, The Royal Institute of \\ Technology \\ Stockholm, Sweden \\ Email: robert@fkt.kth.se \\ ${ }^{4}$ Ecole Centrale d'Electronique, Laboratoire des Techniques Mecatroniques et \\ Electroniques \\ Paris, France \\ Email :mcot@ece.fr \\ ${ }^{5}$ Unisto Oy \\ Tölkkimäentie 11, FIN-13130, Hämeenlinna, Finland \\ Email: unisto@kolumbus.fi
}

\begin{abstract}
Structural vibrations induced by train traffic have to be damped to increase the quality of life in buildings close to railway tracks. The problem becomes more serious in places, where the propagation speed of Rayleigh surface waves is low due to the low elasticity of the soil. To overcome the problem it has been proposed different vibration isolation barrier constructions, which may be composed of sheet piles, artificial gravel layers and air cushion walls to modify the waves traveling along the ground. Because the barrier lines may be relatively long it has been developed an automatic sheet piling system to make the installation fast and economical.
\end{abstract}

Keywords : railway foundations, wave barrier, ground vibrations, sheet piling

\section{INTRODUCTION}

Ground vibrations excited by moving vehicles like cars and trains are disturbances, which reduce the quality of life and working conditions in buildings close to heavily loaded roads and tracks [4]. Architectural damages are also long term consequences of vibrations especially in case of historically valuable buildings. In order to avoid extreme vibration levels, sometimes the maximum train speeds must be limited dramatically in such areas. The problem has been understood to be so serious that new international standards are under preparation work in European Communities for stating limits to acceptable vibration levels. This is an important element leading towards environmentally friendly surface traffic especially in the neighborhood of highly populated urban towns. On the other hand, demands to increase the performance of ground transportation are forcing the expedition and railway companies to use heavy wagons with increasing speeds. It has been observed that higher speeds lead to higher structural and ground responses especially in case of soft soil [3]. Because this development is in conflict with both building protection and environmental requirements it has been initialized research work to find out technical ways to reduce ground vibrations close to railroads. There are two leading strategies in vibration reduction: a) to modify the vibration excitation mechanism b) to modify the vibration response before the waves reach the object to be protected. The design problem is also different when 1) building a completely new railroad or 2) when upgrading an existing one to higher speed class. Because the combinations a1 and $\mathrm{a} 2$ are related to the railway foundation design this paper is concentrated to combinations b1 and b2 e.g. to the question of how to damp the wave motion before the object building in case of new or existing railroad. The main elements of this vibratory system are shown in the topology drawing in figure 1 . 


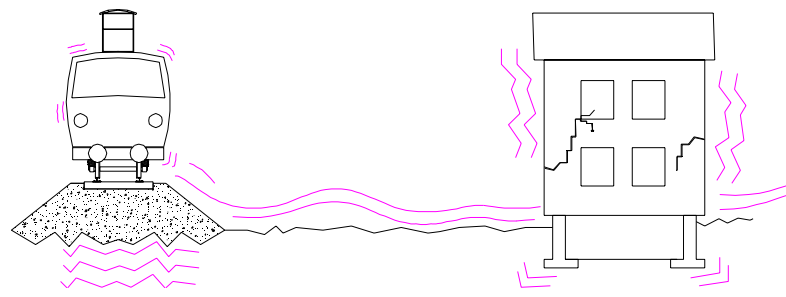

Figure 1. Main elements in train-induced structural vibration problem.

It has been introduced and used both stiff (concrete [1], [2] ) and soft (air cushion [7]) ground vibration isolator barriers as well as medium hard (barrier walls [3]) between the vibration source and object. According to the field tests the methods mentioned have been shown to be relatively effective in their primary function and, therefore, it has opened the discussion on how these structural elements could be installed also in a cost-effective way. Costs include in this case all costs related to materials, machinery, brakes in traffic flow, energy consumption and recycling. Because the complete track line length to be isolated may be several kilometers the most economical solution is worth of deep investigation. During this work it has been found a very promising work method, namely excavator-based sheet piling (figure 2, [5]). This method utilizes automatic control to repeat the correct drive line when constructing complete sheet pile walls (figure $3,[6]$ ).

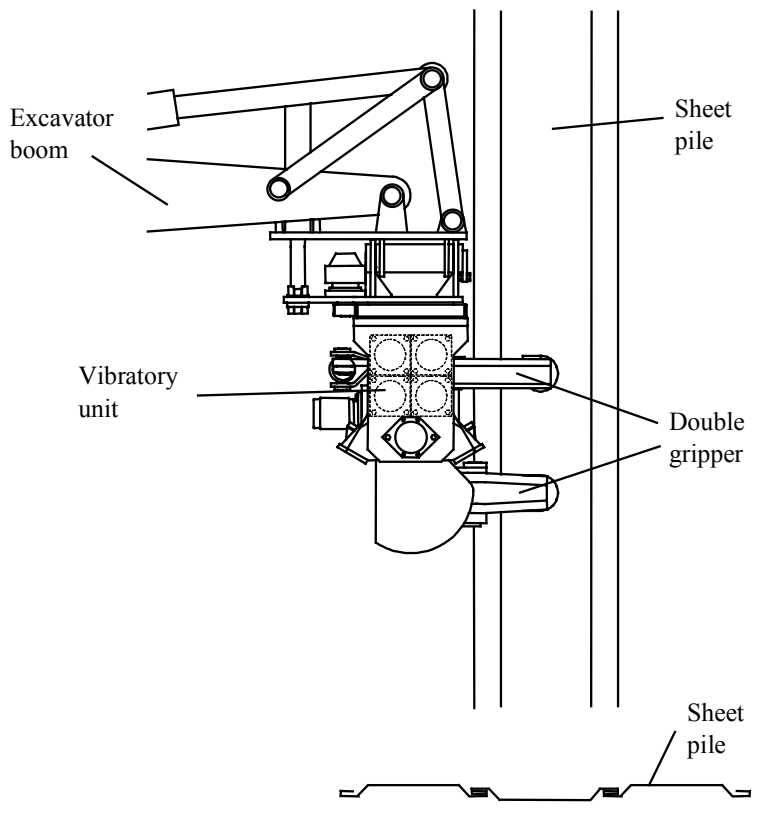

Figure 2. Excavator-mountable sheet-piler with sidegripper [5].

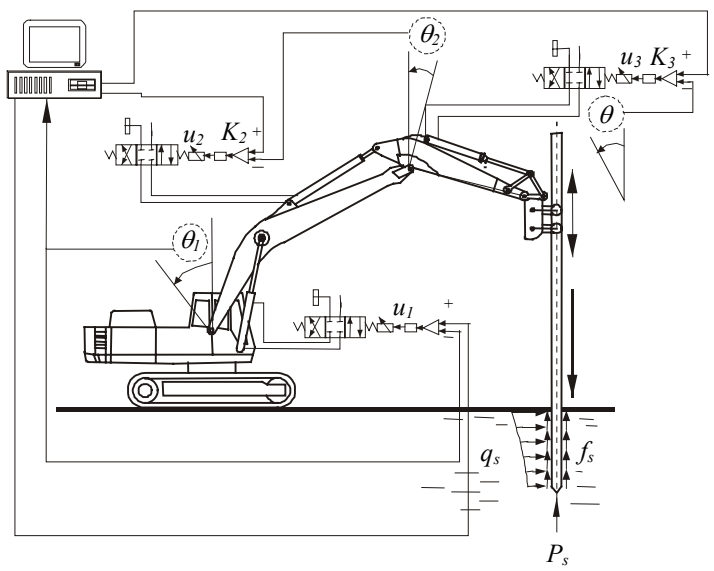

Figure 3. Excavator-based sheet-piler with automatic drive line steering system [6].

In this particular application the potential to use automatic sheet-piling method is exceptionally good for the following reasons:

1. Vibratory sheet piling can be used in soft clay soils only, in which the problem of high wave response also exists.

2. The rail track can be used as a mechanical guiding element to keep the wall-track distance constant.

3. The walls can be temporary or permanent and may be combined flexibly with other foundation materials or elements.

4. The installation method must be fast to minimize the disturbances of traffic flow.

The purpose of this paper is to develop an intelligent work method based on automatic sheet piling to produce different barrier constructions for damping the train-induced waves. The complete work may be divided in to three different subtasks:

1. The development of the barrier construction.

2. The development of the automatic work process.

3. The development of the machine system.

\section{BARRIER DEVELOPMENT}

Barrier construction may be developed under the condition that the whole work cycle should be carried out with excavator and sheet piler only. This is a limitation in the development but, on the other hand, a good starting point, because similar process has already shown its feasibility in foundation works of buildings [5]. Possible combinations, where sheet pile walls and air cushion layers work together, are shown in figure 4. 


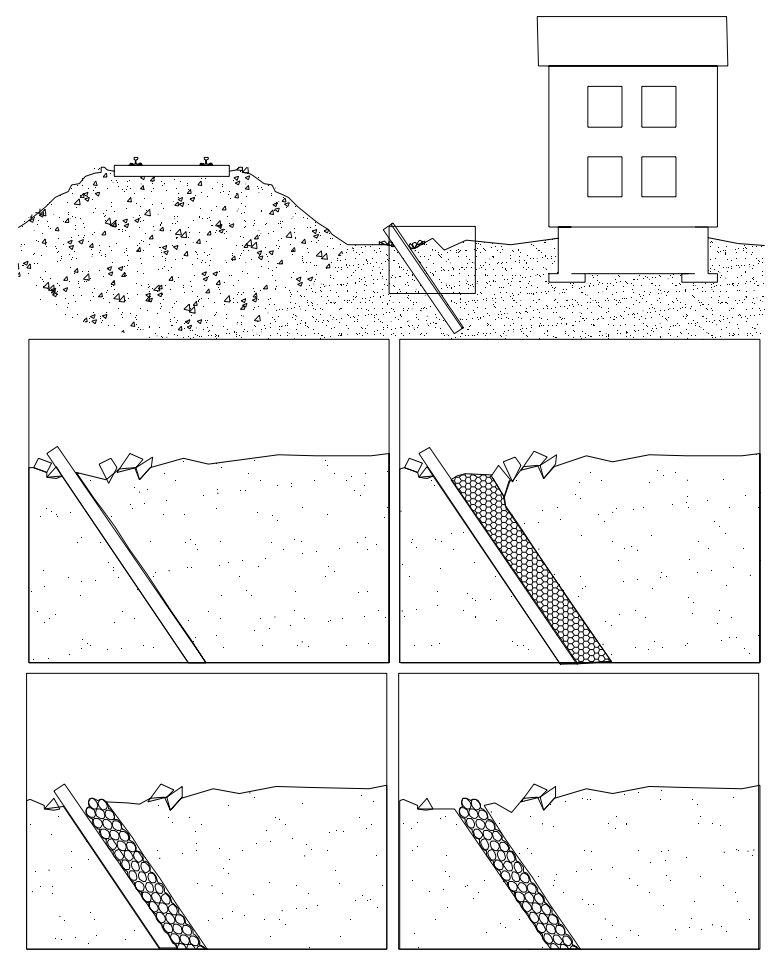

Figure 4. Barrier walls based on different combinations of sheet pile walls and air cushions.

The effectiveness of the barrier may be measured in its ability to modify or damp the surface waves induced by the train motion. In Rayleigh surface waves the particle motion has both horizontal and vertical components [1],[2]. Because the sheet pile wall as a metallic object is very stiff axially, but not in the bending direction, it may cause the following boundary conditions at soil-pile interfaces: Sliding condition in tangential direction and locking condition in normal direction.

Let us consider, for simplicity, the situation as a plane problem of elastic half space of soil material. The field equation may be written with respect to soil displacement vector $s$

$$
\rho \ddot{\boldsymbol{s}}=\boldsymbol{L}(\boldsymbol{s})
$$

where $\boldsymbol{L}$ is the differential operator of elastic forces in soil continuum.

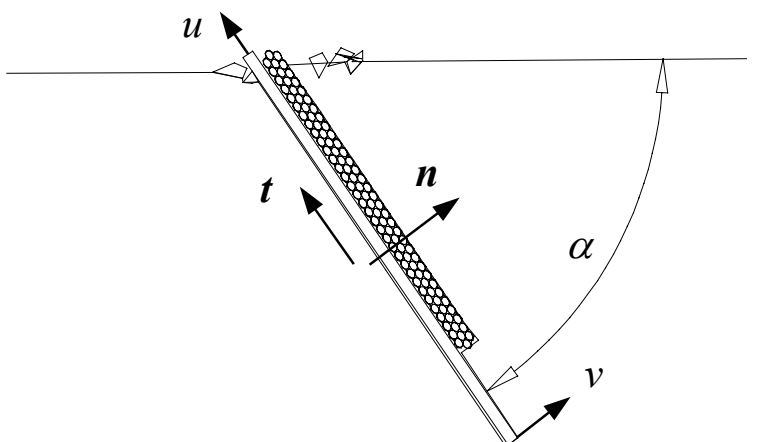

Figure 5. Elements in the dynamic interaction problem between soil, sheet pile wall and isolation layer.
The sheet pile wall is hit in to the soil at a desired angle $\alpha$ (see figure 5) defining the unit vectors for normal $\boldsymbol{n}$ and tangential $\boldsymbol{t}$ directions of the interface. Similarly, the motion components $u$ and $v$ of sheet pile wall in axial and bending directions are governed by wide beam differential equations

$$
\begin{aligned}
& \rho A \ddot{u}=L_{l}(u) \\
& \rho A \ddot{v}=L_{2}(v)
\end{aligned}
$$

The sliding boundary condition is frictional so that shear stresses winning the adhesion or friction capacity $c_{a}$ of the interface may lead to sliding condition instead of sticking. If we use notation $\sigma$ for the stress tensor, this may be written in form

$$
\boldsymbol{n}^{T} \boldsymbol{\sigma} \boldsymbol{t}=\operatorname{sgn}\left(\boldsymbol{t}^{T} \dot{\boldsymbol{s}}-\dot{u}\right) c_{a}
$$

for sliding but for sticking condition

$$
\boldsymbol{t}^{T} \boldsymbol{s}=u
$$

The locking boundary condition connects the motion of soil particles to the motion of the sheet pile in normal direction

$$
\boldsymbol{n}^{T} \boldsymbol{s}=v
$$

If an air cushion bed will be used, it should be installed against the sheet pile wall at the building side, because installing to track side may possibly lead to track settlements later. Boundary condition between the sheet piles and back side soil field is in this case simply an elastic layer condition in momentum form

$$
\begin{aligned}
& \boldsymbol{n}^{T} \boldsymbol{\sigma n}=k_{n}\left(\boldsymbol{n}^{T} \boldsymbol{s}-v\right) \\
& \boldsymbol{t}^{T} \boldsymbol{\sigma n}=k_{\tau}\left(\boldsymbol{t}^{T} \boldsymbol{s}-u\right)
\end{aligned}
$$

Under these conditions the angular orientation of the sheet pile wall is a very interesting parameter, because the wave profile will be modified significantly. Analysis of the barrier performance may be carried out using finite elements [3]. In FE computations it is possible to model the whole topology and dynamic loads including the track excitation, slopes, barriers, building and the soil field for analyzing how the wave will travel from the source to the foundation of the building.

\section{WORK PROCESS DEVELOPMENT}

Sheet piling by side-grip is a work process, in which the working cycle typically consists of phases (see figure 6):

1. Off-loading the piles from the lorry.

2. Lifting and transporting the piles to the driving place. 
3. Giving to the piles a desired position and orientation.

4. Hitting the piles in to the ground.
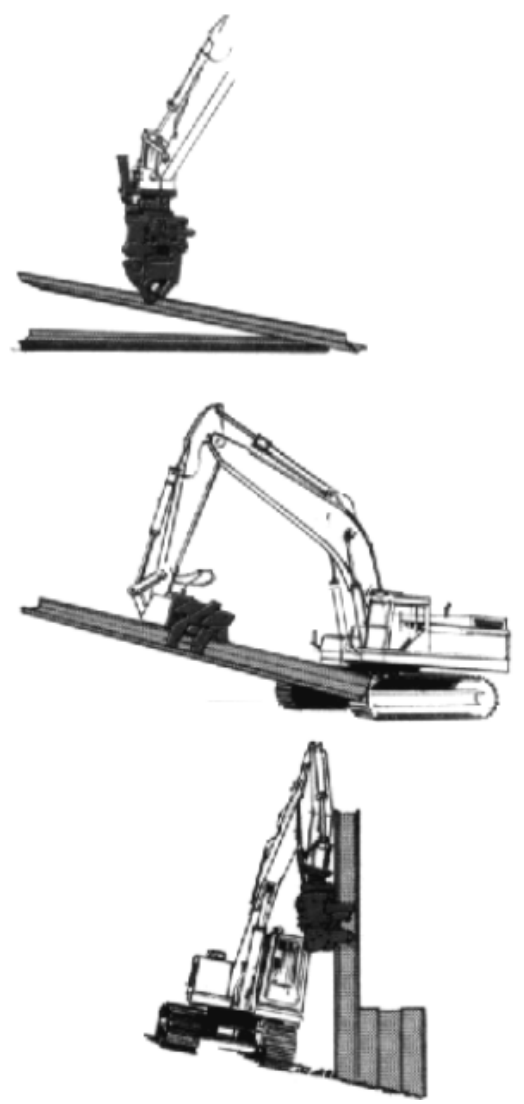

Figure 6. Work phases in side-grip piling method.

Conventionally there has been a need of an excavator, a crane and a piler and a number of $3 \ldots 4$ workers to do the job. In contrast to that in Movax side-grip piling method only one operator and one excavator-mounted piler can do the whole work process. This advantage is based on the integration of vibratory and gripper units in one compact device, which can do flexibly all the materials handling, manipulation, positioning, automatic steering and driving tasks required.

Adaptation of side-grip piling method to railway construction applications is relatively straightforward.

The work process could include phases:

1. Using the gripper take the pile from the wagon.

2. Using the positioning system move the pile in desired position and orientation.

3. Using the steering system drive the pile in to the ground

4. Drive the wagon (or excavator) along the track a distance corresponding to the pile width.

5. Repeat phases $1 \ldots 4$ to reach total distance of one air cushion element.

6. Using the quick hitch adapter system replace the piler by the bucket.
7. Using the automatic slope digging mode remove the soil material away to make a space for the air cushion element. Use the excavated soil to fill the previous dig place.

8. Using the bucket lift and install the air cushion element in parallel contact with the sheet pile wall.

9. Replace the bucket by the sheet-piler.

10. If using temporary sheet pile walls drive the pile out from the ground and continue from step 2 .

11. If using permanent sheet pile walls start from step1.

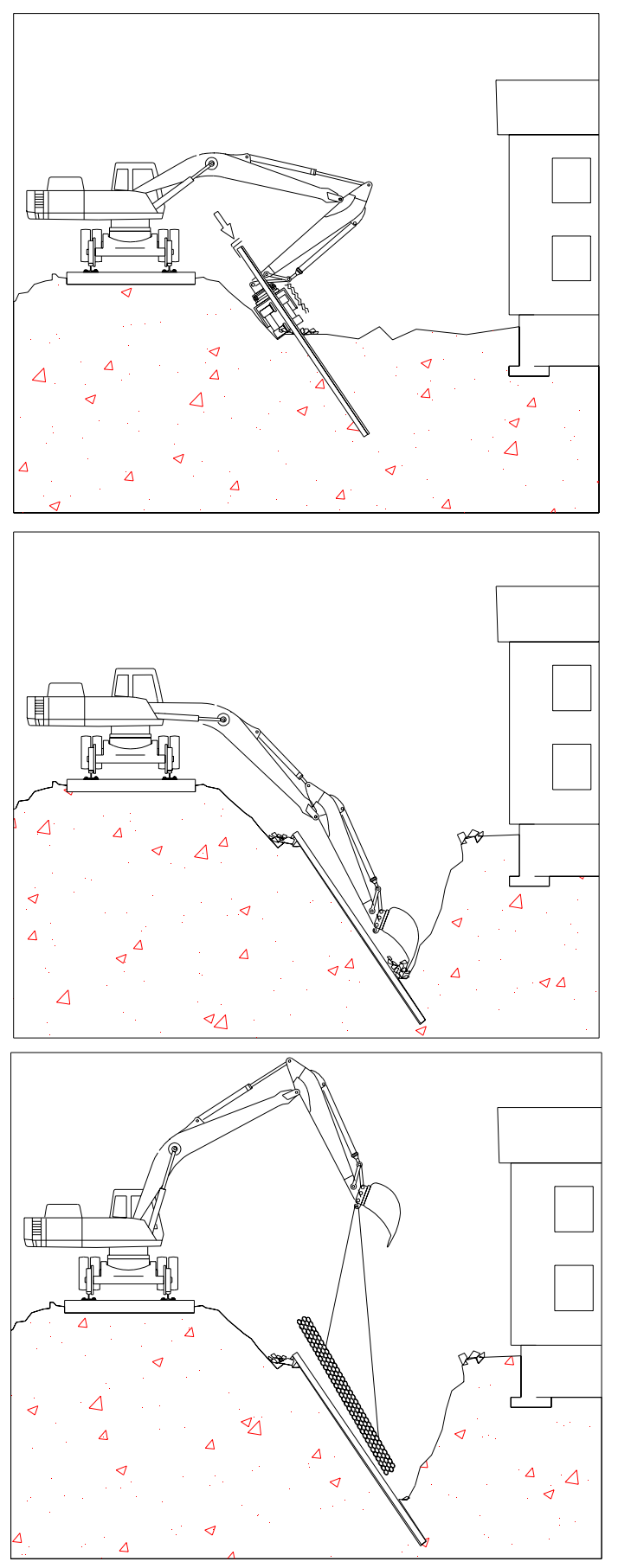

Figure 7. Barrier installation by automatic sheetpiling system. 
This kind of work process can be understood as a window traveling slowly along the track. The steps are illustrated as side views in figures 7 and 8.. The process can be continued flexibly so far as the terrain and soil material are suitable for sheet piling.

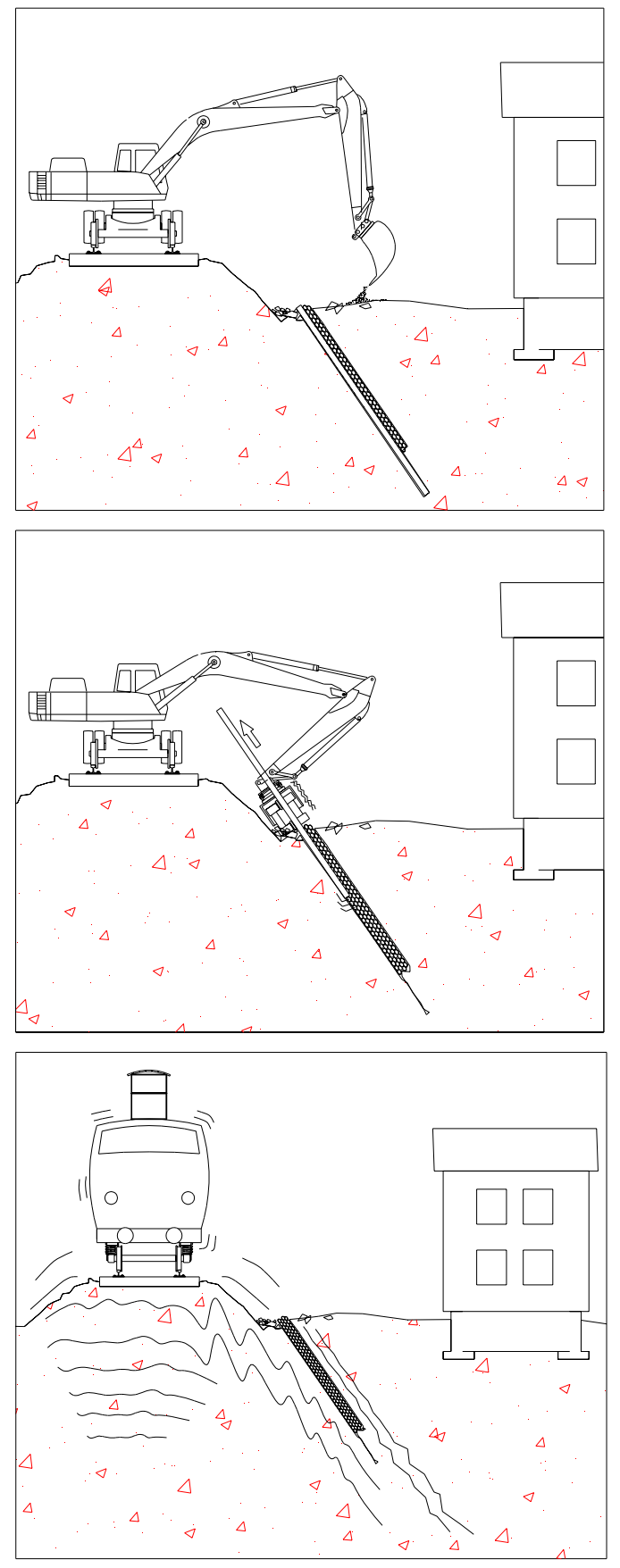

Figure 8. Finishing works in barrier installation.

Work costs in this method are proportional to the earth volumes excavated. This volume may be computed approximately by formula

$$
V=1 / 2 \alpha L b^{2}
$$

where $L$ is the total wall length and $b$ is the depth dimension of the isolation layer in pile direction (see figure 9).

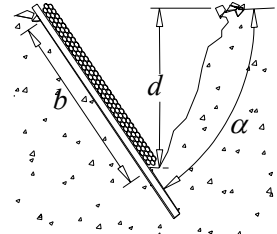

Figure 9. Volume of excavated soil.

As the barrier performance in damping the wave motion is depending on the vertical depth

$$
d=b \sin \alpha
$$

one has to compromise between the work costs and barrier effectiveness.

\section{SYSTEM DEVELOPMENT}

Movax piler has been originally developed for an optionally accessory to an hydraulic excavator. The device can be mounted also to other booms, which have the standard bucket interface. On the other hand, there is available track wheels for excavators also so that the along track mobility of the boom can be solved easily (see figure 10a).

Main advantages of the use of excavator are of course the best suitability for digging and piling works but a wagon is still needed for transporting the piles to the place where the current working window is. Another problem is to find a platform, where to keep the bucket or piler when the other tool is in usage and the other one has to be temporarily stored to wait for the next working step.

Railway companies have also mobile maintenance wagons with their own power source for driving purposes. Another Diesel driven hydraulic power unit could be added to the wagon and its power supply could be used for the boom and pile driving. This machine lay-out is drawn in figure $10 \mathrm{~b}$.

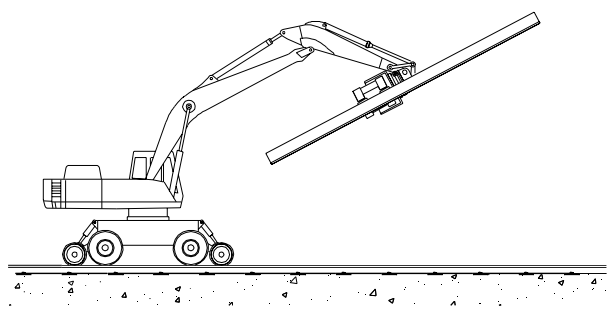

a)

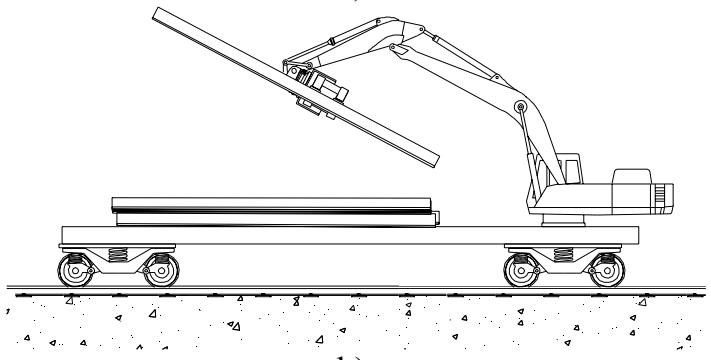

b)

Figure 10. a) An excavator moving on railway track and $b$ ) wagon-based digging and sheet piling system. 
The main elements in the automation system are the upper level supervising system, the boom steering system, pile driving system and the vehicle driving system.

The upper level supervising system communicates with the human operator for reporting the system state and asking permissions to continue with the next phase. One important element in this task is a monitoring system that makes diagnosis of disturbances observed in individual work phases in the complete work cycle.

The boom-controlling system fully utilizes the earlier development work, in which the bucket pin of the boom tracks a desired trajectory in a desired inclination angle. In this particular case the system has to steer the pile to follow straight line in a given orientation angle. Boom motion is controlled by means of inverse kinematic algorithm based on boom position measuring by gravitational angular sensors. Initial positioning can be done semi-automatically so that the drive line and piler orientation will be found automatically but the axial positioning will be done manually. To guarantee that the relative position of the gripper and the pile will remain constant pile after pile the grip has to be taken from a known reference place before the steering. After each pile the excavator or the wagon has to be moved along the track a displacement same as the pile width.

Boom controller can be used also in the digging work so that the bucket motion follows the surface of the building side of the sheet pile wall. This makes a significant time saving in digging.

During the pile driving the upper level controller unit has to monitor the penetration speed giving also a diagnosis of possibly found hard obstacles that prevent the pile to penetrate. Existence of large stones is of course a weakness in the whole method.

Based on earlier experiences of the piler steering in foundation works, the possibilities to fully robotize the complete work process are relatively poor, because the work object and the work space are not so precisely known as in industrial applications. So, a realistic step of the development of this barrier wall installation system could be a human-assisted system that better fits to this partly unstructured work environment. Human operator could control the changes between the work phases and also fine adjust the local positioning tasks while within each task the lower level controller could work automatically.

\section{CONCLUSIONS}

The problem to find out a low-cost method to install barrier walls against train-induced ground vibrations has been under investigation. The purpose is to isolate buildings from the traveling Rayleigh surface waves. This usually happens when the soil consists of soft layers of clay. Such places are locating very often in coastal places, where the soil originates from the sea bottom sediments or erosion sludge conveyed by rivers. One promising work method is sheet-piling, in which case the barrier has to be composed of sheet-pile wall with soft isolation layer at its building side. The purpose of the wall is to reduce the amount of soil masses to be removed and also to support the isolation layer. Isolation material could be air cushion or granular material like artificial gravel. The installation work can be carried out by computer controlled boom system, which allows drive the pile wall in prescribed inclination angle. The boom is equipped with an integrated gripper-driver unit and may belong to an excavator with track wheels or it may be mounted on a customized wagon. By changing cyclically the bucket and sheet piler, the work process can run in piling-digging-layering-filling phases semiautomatically, where the operator assists changes from one internally automatic task to a next one.

\section{REFERENCES}

[1]Ahmad, S. and Al-Hussaini, T. M. Simplified Design for Vibration Screening by Open and InFilled Trenches, Journal of Geotechnical Engineering (1991) 117(1), pp. 67-88.

[2] Al-Hussaini, T. M. and Ahmad, S. Design of Wave Barriers for Prediction of Horizontal Ground Vibration, Journal of Geotechnical Engineering (1991) 117(4), pp. 616-636.

[3] Bahrekazemi, M. \& Bodare, A., Reduction of Train-Induced Ground Vibrations by Lime-Cement Columns, submitted to the Seventh International Workshop on Railway Noise, Solving Urban Rail Noise and Vibration Problems, Portland, Maine USA, October 24-27 2001.

[4] Dowling, C.H., Effects of ground motions from high-speed trains on structures, instruments, and humans. In Wave 2000, Chouw \& Schmid (eds), Balkema, Rotterdam, 2000.

[5] Keskinen, E.K., Keskiniva, M., Raitaniemi, M., \& Raunisto, Y., Simulation-based design of geotechnical work machinery: Development of a next-generation pile driving system. Ninth World Congress on the theory of Machines and Mechanisms, Milano, August 30-31 to September 12, 1995 .

[6] Keskinen, E., Launis, S., Cotsaftis, M. \& Raunisto, Y., Performance Analysis of Drive Line Steering Methods in Excavator-Mounted SheetPiling Systems. Computer-Aided Civil and Infrastructure Engineering 16 (2001) 229-238.

[7] Massarsch, R., \& Ersson, L.O., Vibrationsisolering i jord. Internal report, Division of soil and rock mechanics, The Royal Institute of Technology, Sweden, 1985. 